\title{
Palliative and end-of-life care education in Canadian emergency medicine residency programs: A national cross-sectional survey
}

\author{
Jared Baylis, MD*†; Devin R. Harris, MD, MHSc ${ }^{* \ddagger}$; Charlie Chen, MD, MEd ${ }^{\ddagger \S ; ~ D a n i e l ~ K . ~ T i n g, ~ M D * † \ddagger ; ~}$

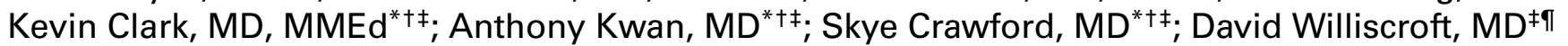

\begin{abstract}
CLINICIAN'S CAPSULE
What is known about the topic?

Palliative medicine is increasingly encountered in an emergency medicine setting, and emergency medicine residents desire further training in this field.

What did this study ask?

How many postgraduate emergency medicine programs

in Canada have an existing palliative medicine curriculum? What did this study find?

A minority $(38.5 \%)$ of emergency medicine programs report having a formal palliative medicine curriculum, and the contents are variable.

Why does this study matter to clinicians?

It will be important to define how trainees will achieve competence in palliative medicine in the emergency department.
\end{abstract}

\section{ABSTRACT}

Objectives: Emergency physicians play an important role in providing care at the end-of-life as well as identifying patients who may benefit from a palliative approach. Several studies have shown that emergency medicine (EM) residents desire further training in palliative care. We performed a national cross-sectional survey of EM program directors. Our primary objective was to describe the number of Canadian postgraduate EM training programs with palliative and end-of-life care curricula.

Methods: A 15-question survey in English and French was sent by email to all program directors of both the Canadian College of Family Physicians emergency medicine (CCFP(EM)) and the Royal College of Physicians and Surgeons of Canada emergency medicine (RCPSC-EM) postgraduate training programs countrywide using FluidSurveys ${ }^{\mathrm{TM}}$ with a modified Dillman approach.
Results: We received a total of 26 responses from the 36 (response rate $=72.2 \%$ ) EM postgraduate programs in Canada. Ten out of 26 (38.5\%) programs had a structured educational program pertaining to palliative and end-of-life care. Lectures or seminars were the exclusive choice to teach content. Clinical palliative medicine rotations were mandatory in one out of $26(3.8 \%)$ programs. The top two barriers to implementation of palliative and end-of-life care curricula were lack of time $(84.6 \%)$ and curriculum development concerns (80.8\%).

Conclusions: Palliative and end-of-life care training within EM has been identified as an area of need. This cross-sectional survey demonstrates that a minority of Canadian EM programs have palliative and end-of-life care curricula. It will be important for all EM training programs, RCPSC-EM and CCFP(EM), in Canada, to develop an agreed upon set of competencies and to structure their curricula around them.

\section{RÉSUMÉ}

Objectif: Les urgentologues jouent un rôle important dans la prestation des soins de fin de vie ainsi que dans le repérage des patients susceptibles de profiter de soins palliatifs. D'après plusieurs études, les résidents et résidentes en médecine d'urgence (MU) désirent recevoir une formation approfondie en soins palliatifs. Une enquête transversale a donc été menée à la grandeur du pays parmi les directeurs de programme de $\mathrm{MU}$, et avait pour objectif principal de dénombrer les programmes de formation de cycle supérieur en MU, au Canada, offrant des curriculums en soins palliatifs et en soins de fin de vie.

Méthode: Un formulaire d'enquête de 15 questions, rédigé en français et en anglais, a été envoyé par courriel à tous les directeurs de programme de formation de cycle supérieur en $\mathrm{MU}$, au pays, tant à ceux du Collège des médecins de famille du Canada (CMFC; certificat en MU) qu'à ceux du Collège royal des médecins et chirurgiens du Canada (CRMCC); I'enquête

From the *Department of Emergency Medicine, Kelowna General Hospital, Kelowna, BC; Interior Health Authority, Kelowna, BC; $\neq$ University of British Columbia, Vancouver, BC; §Fraser Health Authority, Vancouver, BC; and ILions Gate Hospital, North Vancouver, BC.

Correspondence to: Dr. Jared Baylis, Kelowna General Hospital, Department of Emergency Medicine, 2268 Pandosy St., Kelowna, BC V1Y 1T2; Email: jbaylis@alumni.ubc.ca

(c) Canadian Association of Emergency Physicians 
a été menée à l'aide du logiciel FluidSurveys ${ }^{M C}$ selon une version modifiée de la méthode de Dillman.

Résultats: Sur les 36 directeurs de programme de formation de cycle supérieur en MU, offerts au Canada, 26 ont répondu au questionnaire (taux de réponse : 72,2\%). Parmi ces derniers, $10(38,5 \%)$ ont indiqué avoir un programme structuré de formation en soins palliatifs et en soins de fin de vie. Toutefois, les méthodes d'enseignement du contenu se limitaient aux cours magistraux et aux séminaires. Quant aux stages cliniques en médecine palliative, ils n'étaient obligatoires que dans un seul programme sur vingt-six (3,8 \%). Les deux principaux obstacles à la mise sur pied de curriculums en soins palliatifs et en soins de fin de vie étaient le manque de temps $(84,6 \%)$ et des préoccupations concernant l'élaboration de ces curriculums $(80,8 \%)$.

Conclusion: La formation en soins palliatifs et en soins de fin de vie en MU présente des lacunes. II ressort de l'enquête transversale qu'une minorité de programmes en MU au Canada offre des curriculums en soins palliatifs et en soins de fin de vie. II serait donc primordial que les responsables de ces programmes de formation en MU, tant ceux du CMFC que ceux du CRMCC, s'entendent sur un ensemble de compétences à acquérir en la matière et qu'ils élaborent des curriculums en conséquence.

Keywords: curriculum, emergency medicine, medical education, palliative care, terminal care

\section{INTRODUCTION}

The emergency department (ED) may not be seen as the ideal place for initiation of palliative care and end-of-life care, yet up to $40 \%$ of patients with end-of-life concerns present to the ED in the last 2 weeks of life. ${ }^{1,2}$ Emergency medicine (EM) physicians play an important role in providing care at the end-of-life ${ }^{3}$ and identifying patients who may benefit from a palliative approach. Palliative care is relief of symptoms that restrict a patient's quality of life ${ }^{2}$ and thus it falls firmly within the realm of EM. This may include end-of-life care instituted when the patient is predictably in their final weeks of life and a cure is no longer considered achievable. ${ }^{4}$ Goals for ED patients near the end-of-life include pain management and management of other symptoms, including shortness of breath, nausea, fatigue, and depression. Even when established goals of care preclude hospital-based care, an ED visit may be sought due to family distress, ${ }^{2}$ presenting the EM physician with a complex symptom management, disposition planning, and goals of care scenario. These patients and their families require straightforward and compassionate communication, empathy, reassurance, and solace. ${ }^{5}$

Nevertheless, the role and content of palliative care education for EM physicians remains ambiguous. Several groups have called for increased education around palliative care and end-of-life care in the ED. ${ }^{3,6-10}$ Ninety-four percent of EM physicians report a need for education in dealing with death and dying. ${ }^{11}$ Several studies have shown that $\mathrm{EM}$ residents desire further training in palliative care, ${ }^{8,12,13}$ and $54 \%$ of EM residents report never undergoing a rotation in palliative care. ${ }^{14}$ Completion of a fellowship in palliative medicine has been associated with increased comfort in managing terminally ill patients. ${ }^{14}$

At the time this study was designed, there was no consensus on competencies that a Canadian EM resident should possess in palliative and end-of-life care in the ED. In recent months, Canadian EM programs in the Royal College of Physicians and Surgeons of Canada (RCPSC-EM) stream have transitioned to the new Competence by Design curriculum. ${ }^{15}$ Under this model, training is broken down into stages, each of which has its own set of entrustable professional activities (EPAs) detailed by accompanying milestones. We will be discussing EPAs and competencies interchangeably. The list of EPAs for RCPSC-EM includes one that states: "Providing end-of-life care for a patient"16 (see Appendix 1). Within the Canadian College of Family Physicians Enhanced Training in Emergency Medicine, CCFP(EM), program, there are no listed competencies that pertain directly to palliative and end-of-life care. ${ }^{17}$ To our knowledge, there has been no evaluation of current curricular content or whether competencies are being addressed; furthermore, there is no standardized set of competencies that apply to both the RCPSC-EM and CCFP(EM) training streams. At the time of this study, the United States Accreditation Council for Graduate Medical Education's (ACGME) list of EM milestones for the evaluation of resident physicians did not include any milestones directly pertaining to palliative or end-of-life care. ${ }^{18}$ However, an expert, multidisciplinary panel created a curriculum called $E d u$ cation in Palliative and End-of-Life Care in Emergency Medicine (EPEC-EM) that contains a comprehensive list of learning objectives for palliative and end-of-life 
care in EM. ${ }^{19}$ Several educational models have been designed to educate residents in areas such as death notification, ${ }^{20}$ but this is a narrow aspect of palliative care. Many other resources are targeted primarily at the practising physician or registered nurse. ${ }^{9,21}$

We performed a national cross-sectional survey of EM program directors. Our objectives were to describe the number of Canadian postgraduate EM training programs with palliative and end-of-life care curricula and to describe what these curricula entailed. We hypothesized that if variability in training could be compared and contrasted, we could begin to establish and address required palliative and end-of-life care competencies for the modern EM physician and design curricula around these.

\section{METHODS}

From October to December 2016, a national crosssectional survey was conducted to assess existing palliative and end-of-life care curricula in Canadian RCPSC$\mathrm{EM}$ and $\mathrm{CCFP}(\mathrm{EM})$ programs. Our primary outcome was whether Canadian postgraduate EM training programs had structured palliative and end-of-life care curricula. The study was approved by the Interior Health Research Ethics Board and the University of British Columbia Clinical Research Ethics Board (2016-17-026-H).

\section{Study population}

All 36 Canadian EM program directors were surveyed, 19 RCPSC-EM and 17 CCFP(EM), including programs with sites distributed in geographical locations from the main centre.

\section{Survey development}

The survey was developed in consultation with the author group, including specialists in palliative medicine, $\mathrm{EM}$ (CCFP(EM) and RCPSC-EM), and medical education. It was pilot tested on two staff EM physicians at the University of British Columbia for comprehension and content validity. To our knowledge, there were no previously derived or validated survey tools for palliative and end-of-life care education in EM. An independent professional language translator translated the survey and recruitment materials from English to French.

The survey included dichotomous, Likert-type, and open-ended questions (see Appendix 2). Domains within the survey tool included clinical and non-clinical palliative and end-of-life care experiences, palliative and end-of-life care educational objectives, barriers to implementation of palliative and end-of-life care curricula, assessment of residents after curricular completion, and demographics. We defined the presence of a structured palliative care educational program as at least 3 hours of lecture and/or seminar based non-clinical education over the course of an academic year. Educational objectives were assessed with questions from the EPEC-EM ${ }^{19}$ objectives. The EPEC-EM objectives were used as a surrogate because, to our knowledge, at the time of this survey, there were no Canadian-based comprehensive palliative and end-of-life care curriculum objectives available that pertain specifically to EM.

Five-point Likert scales were used to assess each program's coverage of the EPEC-EM curriculum objectives in clinical and non-clinical domains. Responses were collated into Likert scores of 0-2 (not well addressed) and 3-5 (well addressed).

\section{Survey administration}

All potential participants received an information letter and provided informed consent prior to their enrolment in the study. A 15-question survey in English and French was sent by email to all program directors of both CCFP (EM) and RCPSC-EM postgraduate training programs countrywide using FluidSurveys ${ }^{\mathrm{TM}}$ with a modified Dillman approach. ${ }^{22}$ Email addresses were obtained through the Canadian Resident Matching Service website. Program directors were emailed with a live link to the survey up to three times between October and December 2016. Participation was incentivized with a \$20 CAD coffee card for the first 10 respondents and a draw for five remaining cards for any additional respondents. Finally, a follow-up phone call was made to program directors who had not yet responded 2 weeks prior to the survey closing.

\section{Analysis}

Contingency analysis was performed using the Fisher exact test for the primary outcome. Total annual hours of palliative and end-of-life care educational material were analysed using the median and interquartile range (IQR). A descriptive analysis was also performed. For all statistical analyses, $p \leq 0.05$ (with $95 \%$ confidence intervals) was considered significant. 


\section{RESULTS}

We received a total of 26 responses from the 36 (response rate $=72.2 \%$ ) EM postgraduate training programs in Canada. Fourteen of 19 (73.7\%) CCFP(EM) programs responded, and 12 out of 17 (70.6\%) RCPSC-EM programs responded.

Regarding the primary outcome, 10 out of $26(38.5 \%)$ programs reported having a structured educational program on palliative and end-of-life care. There was no significant difference between RCPSC-EM and CCFP (EM) programs in the primary outcome $(p=1)$. Educational coverage of the EPEC-EM objectives is displayed in Figure 1.

Of the 10 programs with a structured palliative and end-of-life care educational program, 100\% were either lecture or seminar-based. For the entirety of residency, median total lecture hours were 4 ( $\mathrm{IQR}=4.75$ hours). Median seminar hours were $4(\mathrm{IQR}=$ not applicable due to sample size). No programs used online modules, podcasts, videocasts, or handout materials.

Clinical palliative medicine rotations were mandatory in only one out of $26(3.8 \%)$ programs. However, 4 out of $26(15.4 \%)$ programs offer palliative medicine as a selective rotation out of a short list of options, and 13 out of $26(50 \%)$ programs offer palliative medicine as an elective rotation.
Respondents identified many potential barriers to the implementation of palliative and end-of-life care curricula in EM (Table 1). The top two were a lack of time (84.6\%) and curriculum development concerns (80.8\%). These latter concerns were defined as an inability to keep content current and relevant.

Only 4 out of 26 (15.4\%) programs formally assessed residents in palliative or end-of-life knowledge or skills with some having multiple formal assessment modalities. Three $(75 \%)$ of these programs had feedback after a patient encounter, one $(25 \%)$ had an informal clinical evaluation, and one (25\%) had a formal clinical evaluation such as an objective structured clinical examination (OSCE). One program did not specify how its residents were assessed. Seven out of 26 (26.9\%) programs have had residents complete formal fellowships in palliative care. Three were RCPSC-EM and four were CCFP(EM).

Three $\mathrm{CCFP}(\mathrm{EM})$ programs remarked that there is insufficient time in a 1-year program to have a formal palliative and end-of-life care rotation or curriculum. However, two programs reported that incoming residents have completed training in palliative and end-of-life care during their family medicine training; this included one program that surveyed incoming CCFP(EM) residents over 2 years and found that all had previous formal training in palliative care prior to their EM year.

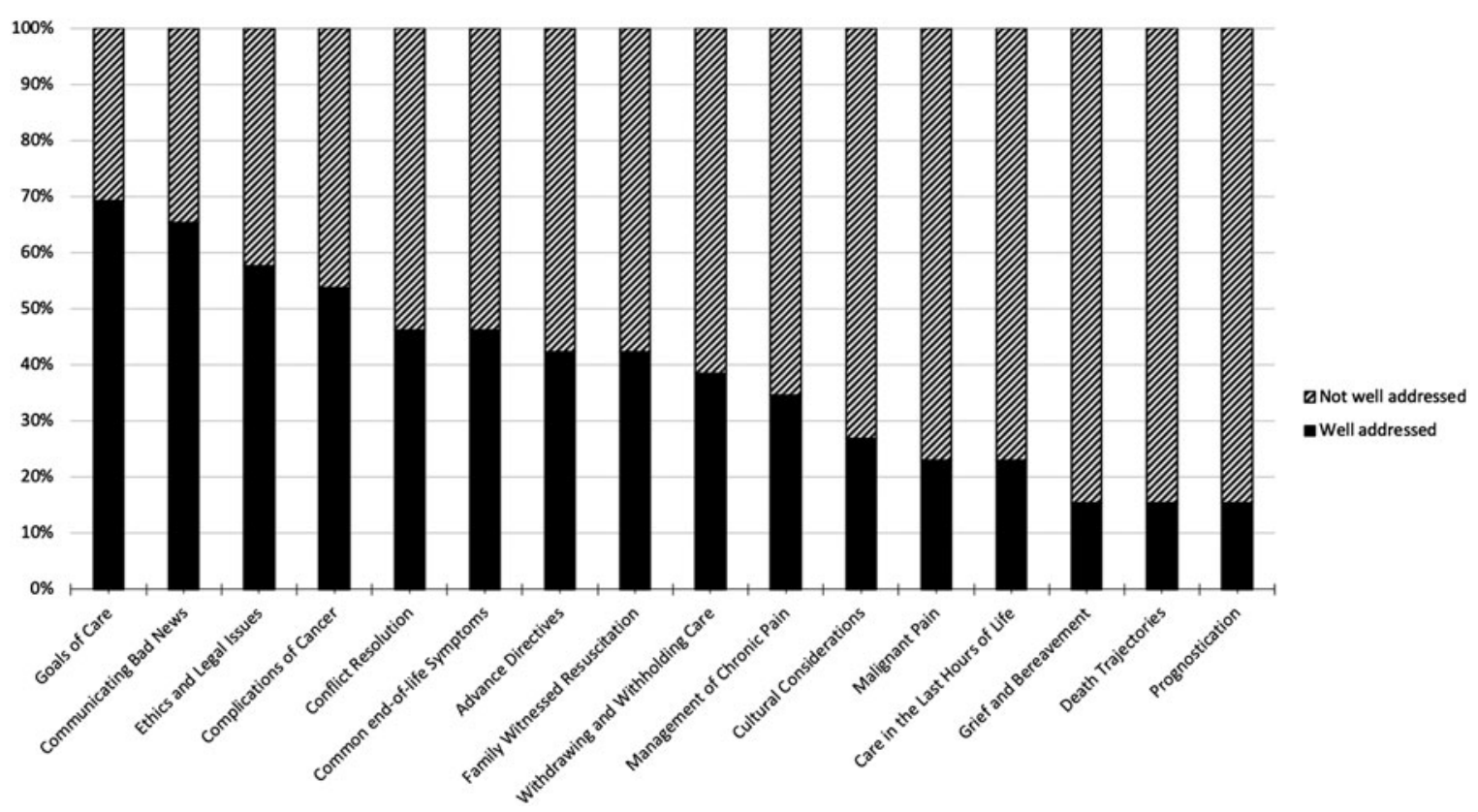

Figure 1. EM program coverage of palliative and end-of-life care objectives. 


\begin{tabular}{|c|c|c|}
\hline Barrier identified & Yes & No \\
\hline Time & $22(84.6 \%)$ & $4(15.4 \%)$ \\
\hline Curriculum development & $21(80.8 \%)$ & $5(19.2 \%)$ \\
\hline Defining learning objectives & $13(50 \%)$ & $13(50 \%)$ \\
\hline Availability of instructors & $13(50 \%)$ & $13(50 \%)$ \\
\hline Expertise & $11(42.3 \%)$ & $15(57.7 \%)$ \\
\hline Funding & $8(30.8 \%)$ & $18(69.2 \%)$ \\
\hline
\end{tabular}

\section{DISCUSSION}

We found that only $38.5 \%$ of EM program directors reported having structured palliative and end-of-life curricula and that curricular content was highly variable. This is problematic in that it is difficult to educate trainees to achieve competence in palliative and end-of-life care when clinical or non-clinical experiences have not been defined. Furthermore, 100\% of the curricula reported are lecture or seminar-based, which may not be the ideal way to teach these nuanced skills. To our knowledge, this study is the first of its kind in Canada and establishes a national landscape of current palliative and end-of-life care curricula in EM training programs.

In the United States, EPEC-EM provides a train-thetrainer, conference style curriculum for emergency providers. ${ }^{19}$ One of their specific goals is to collaborate with program directors in EM to ensure that their trainees receive education around core competencies in palliative and end-of-life care in the ED. In recent months, the American College of Emergency Physicians (ACEP) Palliative Medicine Section has developed a set of milestones, using the ACGME milestone framework, for hospice and palliative medicine for EM residents. ${ }^{23}$ Our results suggest that we do not currently have a similar educational landscape in Canada.

EPEC-EM was developed in the United States; however, a majority of the EPEC-EM objectives are similar to the milestones within the EPA for end-of-life care in the RCPSC-EM curriculum (see Appendix 1). The objectives of advance directives and ethics/legal concerns within EPEC-EM may differ in the Canadian setting. It is important to note that the EPA puts emphasis on end-of-life care and may inadvertently underemphasize other aspects of palliative medicine. Out of the EPECEM objectives, only goals of care, ethics and legal issues, communicating bad news, and complications of cancer were well addressed by a majority of EM programs. These pertain to 4 of the 10 milestones within the EPA for providing end-of-life care (see Appendix 1). The remainder of the milestones were either not assessed by this survey or not well addressed within current curricula. Establishing this baseline serves to provide areas of focus as EM residency programs consider starting or improving their palliative and end-of-life care curricula.

Assessment of trainee competency may prove challenging when EM physicians are reporting a need for further education on the topics covered within the EPA. ${ }^{11,24}$ In the future, assessment of competency may shift to the increasing number of EM physicians specializing in palliative medicine. As of 2018, there are $150 \mathrm{EM}$ physicians in the United States with specialization in hospice and palliative medicine ${ }^{19}$ and both the ACEP and the Canadian Association of EM physicians have sections or committees for ED palliative medicine.

Time was noted to be a significant barrier to palliative and end-of-life care education in the ED in both RCPSC$\mathrm{EM}$ and CCFP(EM) training streams. This is an interesting finding in that the RCPSC-EM program is 5 years in length, whereas the $\mathrm{CCFP}(\mathrm{EM})$ program is 1 year. $\mathrm{CCFP}(\mathrm{EM})$ programs appear to be assuming that their trainees have received palliative medicine training within their family medicine residency. On the other hand, RCPSC-EM trainees will not have had the same experience. It will be important for the RCPSC-EM program to prioritize time for addressing palliative and end-of-life care curricula to ensure that trainees achieve competencies in this important topic.

Simulation has been explored in nursing as an effective method through which to teach palliative medicine concepts. ${ }^{25}$ Methods used in Canadian oncology and palliative medicine postgraduate programs include role playing and simulation. When palliative and end-of-life care curricula are introduced to residents, they should match the needs of the current educational evidence and go beyond lecture/seminar formats. ${ }^{26}$ In addition, postgraduate training programs should engage in bedside teaching and small group sessions, because these approaches are known to be preferred educational methods for palliative medicine in EM. ${ }^{14}$ Only four programs reported any assessment or evaluation of their trainees after palliative and end-of-life care education. In RCPSC-EM programs, this will likely involve direct observation using the end-of-life care EPA, which could occur in a simulation setting. However, in other EM programs, there will need to be a structured 
assessment and/or evaluation to determine whether competency has been achieved.

In discussing palliative and end-of-life care education for EM residents, it is important to recognize how the field is evolving. Due in part to demographic shifts, healthcare needs of Canadians are changing with seniors having a higher need for palliative care services. ${ }^{27}$ Increasingly specialized care may lead patients to present to the ED with novel and unfamiliar medication regimens, or even complications of procedural management such as home paracentesis and thoracentesis catheters.

Another way in which palliative medicine is changing in Canada is with the introduction of medical assistance in dying (MAiD). Patients may present to the ED for symptom management concerns despite ongoing assessment for MAiD and even pending provision. EM learners will need to understand the legal framework around MAiD and their roles and responsibilities within it.

\section{Limitations}

We recognize several limitations in our study. Firstly, our survey was completed by program directors. Although program directors have an overall view of the curriculum of their residency program, they may not have the in-depth knowledge of the specific objectives of their program's palliative medicine curriculum. Program directors may also feel pressure to answer questions favorably to reflect well on their residency program, which can lead to a response bias. EPEC-EM is an American EM palliative medicine course that is designed to include residents. However, its applicability in the Canadian context may be a limitation. Our findings may underestimate the true number of hours of training in palliative care because we did not design our survey to capture experiences of residency training in family medicine prior to $\mathrm{CCFP}(\mathrm{EM})$ training. However, these experiences are in the context of family medicine, which may be distinctly different from the EM setting when it comes to palliative and end-of-life care. Furthermore, CCFP(EM) certificants virtually always practise full-time EM, further calling into question the relevance of family medicine based palliative and end-of-life care education in the EM context. ${ }^{19,28}$

\section{Next steps}

Our study provides a starting point for further research and development of consensus among programs regarding which competencies are necessary for the modern EM physician regardless of training stream. Developing consensus should involve RCPSC-EM, CCFP(EM), and palliative medicine experts. Further research should also examine the patient perspective. Five areas have been identified by patients where quality of end-of-life care could be improved: adequate pain and symptom management, avoiding inappropriate prolongation of dying, achieving a sense of control, relieving the burden of death on family, and strengthening relationships with loved ones. ${ }^{29}$ As suggested by the Improving Palliative Care in Emergency Medicine collaboration, it will be important that individual EM training programs identify a local palliative care champion ${ }^{9}$ and use existing educational resources, such as the RCPSC-EM EPA for end-of-life care to structure educational curricula. These should include multiple clinical and non-clinical educational modalities, such as simulation and small groups.

\section{CONCLUSION}

Palliative and end-of-life care training within EM has been identified as an area of need for the preparation of a competent EM physician. This cross-sectional survey reveals high variability within current palliative and end-of-life care curricula in Canadian EM programs. There are currently developed milestones within the end-of-life care EPA for the RCPSC-EM curriculum. However, a minority of Canadian EM physicians are RCPSC-EM trained, and current curricula address a minority of the milestones within the EPA for providing end-of-life care. As such, it will be important for all EM training programs, RCPSC-EM and CCFP(EM), in Canada, to develop an agreed upon set of competencies and to structure their curricula around this. These curricula should include multimodal educational methods, including bedside teaching, small group sessions, and the development of robust simulation cases specific to patients with palliative needs in the ED.

\section{SUPPLEMENTARY MATERIAL}

The supplementary material for this article can be found at https://doi.org/10.1017/cem.2018.470.

Competing interests: CC reports personal fees from Pallium Canada, outside the submitted work. 


\section{REFERENCES}

1. Barbera L, Taylor C, Dudgeon D. Why do patients with cancer visit the emergency department near the end of life? CMA7 2010;182(6):563-8.

2. Mierendorf SM, Gidvani V. Palliative care in the emergency department. Perm 7 2014;18(2):77-85.

3. American College of Emergency Physicians. Emergency Department Palliative Care. Information Paper; 2012. Available at: https://www.acep.org/globalassets/uploads/uploadedfiles/acep/clinical-and-practice-management/resources/administration/palliative_care_ip_final_june2012_edited.pdf (accessed July 9, 2018).

4. Quest TE, Asplin BR, Cairns CB, et al. Research priorities for palliative and end-of-life care in the emergency setting. Acad Emerg Med 2011;18(6):e70-6.

5. Schears RM. Emergency physicians' role in end-of-life care. Emerg Med Clin North Am 1999;17(2):539-59.

6. Gisondi MA. A case for education in palliative and end-of-life care in emergency medicine. Acad Emerg Med 2009;16(2): 181-3.

7. Rutkowski A. Death notification in the emergency department. Ann Emerg Med 2002;40(5):521-3.

8. Lamba S, Pound A, Rella JG, Compton S. Emergency medicine resident education in palliative care: a needs assessment. 7 Palliat Med 2012;15(5):516-20.

9. Lamba S, DeSandre PL, Todd KH, et al. Integration of palliative care into emergency medicine: the Improving Palliative Care in Emergency Medicine (IPAL-EM) collaboration. 7 Emerg Med 2014;46(2):264-70.

10. Benenson RS, Pollack ML. Evaluation of emergency medicine resident death notification skills by direct observation. Acad Emerg Med [Internet]. 2003 Mar;10(3):219-23. Available from: https://www.ncbi.nlm.nih.gov/pubmed/12615586

11. Schmidt TA, Norton RL, Tolle SW. Sudden death in the ED: educating residents to compassionately inform families. 7 Emerg Med 1992;10(5):643-7.

12. DeVader TE, Jeanmonod R. The effect of education in hospice and palliative care on emergency medicine residents' knowledge and referral patterns. F Palliat Med 2012;15(5):510-5.

13. Smith AK, Fisher J, Schonberg MA, et al. Am I doing the right thing? Provider perspectives on improving palliative care in the emergency department. Ann Emerg Med 2009;54(1):86-93, 93.e1.

14. 'Turner CJ. P135: Canadian emergency medicine residents' training and competency in end-of-life care: a needs assessment. CFEM 2016;18(S1):S123.

15. The Royal College of Physicians and Surgeons of Canada. Competence By Design; 2017. Available at: http://www.royalcollege.ca/rcsite/cbd/competence-by-design-cbd-e (accessed July 11, 2018).

16. The Royal College of Physicians and Surgeons of Canada. EPAs and milestones; 2017. Available at: http://www. royalcollege.ca/rcsite/cbd/implementation/cbd-milestonesepas-e (accessed July 11, 2018).

17. The College of Family Physicians of Canada. Specific standards for family medicine residency programs; 2016. Available at: http://www.cfpc.ca/uploadedFiles/Red\%20Book\% 20English.pdf (accessed July 11, 2018).

18. The Accreditation Council for Graduate Medical Education and The American Board of Emergency Medicine. The Emergency Medicine Milestone Project; 2015. Available from: https://www.acgme.org/Portals/0/PDFs/Milestones/ EmergencyMedicineMilestones.pdf (accessed July 11, 2018).

19. Feinberg School of Medicine: Northwestern University. Education in palliative and end-of-life care. Emergency medicine; 2017. Available at: http://bioethics.northwestern. edu/programs/epec/curricula/emergency.html (accessed July 9, 2018).

20. Quest TE, Otsuki JA, Banja J, et al. The use of standardized patients within a procedural competency model to teach death disclosure. Acad Emerg Med 2002;9(11):1326-33.

21. Pallium Canada. Leap Core: learning essential approaches to palliative care. Pallium Canada. Available at: https://pallium. ca/equip-yourself/courses/ (accessed July 9, 2018).

22. Schaefer DR, Dillman DA. Development of a standard e-mail methodology: results of an experiment. Public Opin Q 1998;62(3):378.

23. Shoenberger J, Lamba S, Goett R, et al. Development of hospice and palliative medicine knowledge and skills for emergency medicine residents: using the Accreditation Council for Graduate Medical Education Milestone Framework. AEM Educ Train 2018;2(2):130-45.

24. Wright RJ, Lowton K, Robert G, et al. Emergency department staff priorities for improving palliative care provision for older people: a qualitative study. Palliat Med 2018;32 (2):417-25.

25. Gillan PC, Jeong S, van der Riet PJ. End of life care simulation: a review of the literature. Nurse Educ Today 2014;34 (5):766-74.

26. Khan K, Pattison T, Sherwood M. Simulation in medical education. Med Teach 2011;33(1):1-3.

27. Hawley P. and Canadian Society of Palliative Care Physicians. How to improve palliative care in Canada: a call to action for federal, provincial, territorial, regional and local decision-makers. Canadian Society of Palliative Care Physicians; 2016. Available at: http://www.cspcp.ca/wp-content/ uploads/2016/11/Full-Report-How-to-Improve-PalliativeCare-in-Canada-FINAL-Nov-2016.pdf (accessed September 7, 2018).

28. CAEP. The Collaborative Working Group on the Future of Emergency Medicine in Canada final report; 2016. Available at: https://caep.ca/advocacy/collaborative-working-groupfinal-report/ (accessed July 9, 2018).

29. Singer PA, Martin DK, Kelner M. Quality end-of-life care: patients' perspectives. FAMA 1999;281(2):163-8. 